\title{
Mutation at the TrkB PLC $\gamma$-docking site affects hippocampal LTP and associative learning in conscious mice
}

\author{
Agnès Gruart, ${ }^{1}$ Carla Sciarretta, ${ }^{2}$ Mauricio Valenzuela-Harrington, ${ }^{1}$ \\ José M. Delgado-García, ${ }^{1}$ and Liliana Minichiello ${ }^{2,3}$ \\ ${ }^{1}$ División de Neurociencias, Universidad Pablo de Olavide, 41013 Sevilla, Spain; ${ }^{2}$ European Molecular Biology Laboratory, Mouse \\ Biology Unit, 00016 Monterotondo, Italy
}

\begin{abstract}
Previous in vitro studies have characterized the electrophysiological properties and molecular events associated with long-term potentiation (LTP), but as yet there are no in vivo data from molecular-level dissection that directly identify LTP as the biological substrate for learning and memory. Understanding whether the molecular pathways required for learning are also those generating LTP when measured directly on the relevant circuit of a learning animal is clearly important, although so far has proved technically difficult. Here, for the first time, we combine highly defined genetic mouse models with behavior and in vivo recordings. We recorded the activity-dependent changes taking place at the CA3-CAl synapses during the acquisition and extinction of a simple form of an associative learning task in mice carrying point mutations on specific docking sites of TrkB receptors $\left(\operatorname{trk} B^{S H C}\right.$, $\left.t r k B^{P L C}\right)$. The learning task consisted of a classical eyeblink conditioning using a trace paradigm. The conditioned stimulus (CS) consisted of a tone and was followed by a periorbital electrical shock as an unconditioned stimulus (US). The US started $500 \mathrm{msec}$ after the end of the CS. We show that a single pulse presented to the Schaffer collateral-commissural pathway during the CS-US interval evoked a monosynaptic field excitatory postsynaptic potential (fEPSP) at the CAl pyramidal cells, with a slope linearly related to learning evolution in controls and trkB ${ }^{S H C}$ mutants, but the relationship was impaired in $t r k B^{P L C}$ mice. These data support a link between the PLC $\gamma$-docking site downstream of TrkB and the activity-dependent synaptic changes evoked at the CA3-CAl synapses during associative learning in conscious mice, and indicate that TrkB PLC $\gamma$-site-activated molecular pathway(s) underlie both associative learning and LTP triggered at the CA3-CA1 synapse.
\end{abstract}

Long-term potentiation (LTP) is to a great extent a well-studied form of synaptic plasticity. It is thought to reveal mechanisms for the acquisition and storage of information by synapses in the hippocampus and other selected brain sites (Bliss and Collingridge 1993; Kandel 2001). The electrophysiological properties and molecular events associated with LTP have been well characterized by in vitro studies (Bliss and Collingridge 1993; Malenka and Nicoll 1999; Lynch 2004). The role LTP may play in learning and memory is a very old question; in 1984, Weisz and colleagues reported evidence that processes similar to LTP may occur in the dentate granule cells of rabbits during classical conditioning of nictitating membrane responses (Weisz et al. 1984). Lately, it has been shown that mice can be trained with trace conditioning paradigms, and that hippocampal CA3-CA1 synapses are involved in the acquisition and extinction of trace conditioning in conscious mice (Takatsuki et al. 2003; Domínguezdel-Toro et al. 2004; Gruart et al. 2006). However, there are no in vivo data from molecular-level dissection that directly identify LTP as the biological substrate for learning and memory. Thus, it is essential to understand whether the molecular pathways required for learning are also those generating LTP when measured directly on the relevant circuit of a behaving animal.

Several receptors have been demonstrated to be important for hippocampal synaptic function and LTP, including the TrkB receptor. TrkB is a member of the neurotrophin receptor tyrosine

\footnotetext{
${ }^{3}$ Corresponding author.
}

E-mail minichiello@embl.it; fax +39-06-90091-272.

Article is online at http://www.learnmem.org/cgi/doi/10.1101/lm.428307. Freely available online through the Learning \& Memory Open Access option. kinase family, whose members play important roles in the developing and mature nervous system in vivo (for review, see Bibel and Barde 2000). Its ligands are BDNF (brain-derived neurotrophic factor) and NT4/5. In $b d n f$ null mutant and forebrainspecific trkB knockout mice, CA3-CA1 hippocampal LTP, measured by in vitro electrophysiology, is impaired (for review, see Schinder and Poo 2000; see also Korte et al. 1995; Patterson et al. 1996; Minichiello et al. 1999; Pozzo-Miller et al. 1999; Xu et al. 2000). Finally, the forebrain-specific deletion of $t r k B$ results in compromised spatial learning ability (Minichiello et al. 1999).

TrkB, upon ligand binding, activates well-known intracellular signaling cascades such as the Ras/MAPK pathway and the phosphoinositide 3 kinase pathway (primarily through binding of Shc/FRS-2 to the juxtamembrane phosphotyrosine 515). Moreover, the recruitment of phospholipase C $\gamma$ (PLC $\gamma$ ) upon TrkB activation (through phosphotyrosine 816 ) potentially upregulates intracellular $\mathrm{Ca}^{2+}$ levels, and activates the calcium/ calmodulin kinase pathway. To understand the signaling pathways that mediate the hippocampal LTP/spatial learning functions of TrkB receptors, we have previously studied mice carrying a point mutation on specific docking sites in the intracellular region of TrkB (the PLC $\gamma$-docking site, $\operatorname{trkB}^{\mathrm{PLC}}$ mice; and the Shcdocking site, trkB ${ }^{\mathrm{SHC}}$ mice), and have shown by in vitro electrophysiology that the TrkB PLC $\gamma$-docking site is necessary to mediate hippocampal LTP (Minichiello et al. 2002). It remains to be determined, however, whether these events occur naturally in the hippocampus during learning. The fact that mice can be trained with trace paradigms, and that hippocampal CA3-CA1 synapses are involved in the acquisition and extinction of trace 
conditioning in conscious mice (Takatsuki et al. 2003; Domínguez-del-Toro et al. 2004; Gruart et al. 2006), makes feasible the study of neural processes affecting cognitive functions in genetically manipulated animals. We applied the classical conditioning of eyelid responses, with a trace paradigm, to control and heterozygous $\operatorname{trkB}$ signaling point mutant mice $\left(+/+, \operatorname{trk} B^{W /+}\right.$ and $t r k B^{S H C /+}, t r k B^{P L C /+}$ ), and determined the involvement of TrkB signaling in the modification of CA3-CA1 synaptic strength in conscious mice during associative learning acquisition. Here, we show that the activity-dependent synaptic changes taking place in the CA3-CA1 hippocampal region in conscious mice during associative learning require the TrkB PLC $\gamma$-docking site. These data provide in vivo evidence that TrkB PLC $\gamma$-site-activated molecular pathway(s) underlie both LTP triggered at the CA3-CA1 synapses and associative learning in conscious mice.

\section{Results}

Learning and hippocampal synaptic potentiation fail to develop in trkB ${ }^{P L C}$ mutants in vivo

To test the contribution of signaling pathways activated downstream of the TrkB receptor to both hippocampal LTP and learning in conscious mice, we chose as a genetic model mice heterozygous for either the Shc- or the PLC $\gamma$-docking site of the TrkB receptor, which lack significant peripheral developmental abnormalities (Minichiello et al. 1998; C. Sciarretta and L. Minichiello, unpubl.). In contrast, mutants homozygous for either the Shc- or the PLC $\gamma$-docking site of the TrkB receptor are hyperactive compared with control mice, mainly due to defects in the inner ear, although development of the central nervous system is normal (Minichiello et al. 1998, 2002). The experimental groups consisted of two control strains $\left(+/+, t r k B^{W /+}\right)$ and two point mutant strains $\left(\operatorname{trkB} B^{S H C /+}, \operatorname{trk} B^{P L C /+}\right)$. The $t r k B^{W /+}$ strain is the direct control for the "knock-in" (KI) strategy used to generate the $\operatorname{trk} B^{P L C /+}$ strain. As previously explained (Minichiello et al. 2002; see Materials and Methods), homozygous mutant $\operatorname{trkB} B^{P L C / P L C}$ and wild-type control $\operatorname{trk} B^{W T / W T}$ mice express the $\mathrm{gp}^{145}$ TrkB receptor at $60 \%$ of the normal amount. This suggests that the $3^{\prime}$ UTR plays a role in the stability of TrkB mRNA; however, the availability of the relevant wild-type KI mice allows us to control for this.

We applied the classical conditioning of eyelid responses, with a trace paradigm, to control and heterozygous trkBsignaling point mutant mice. The trace paradigm applied (Gruart et al. 2006; and see Materials and Methods) consisted of a brief tone presented as a conditioned stimulus (CS), followed, 500 msec later, by an electrical shock presented to the supraorbitary branch of the trigeminal nerve as an unconditioned stimulus (US). Eyelid responses were determined by the electromyographic (EMG) activity of the orbicularis oculi (O.O.) muscle ipsilateral to the US. In parallel we recorded the field excitatory postsynaptic potentials (fEPSPs) at the apical dendrites (stratum radiatum) of hippocampal CA1 pyramidal cells tween groups $(P \leq 0.05)$. evoked by electrical stimulation of the Schaffer collateralcommissural pathway during habituation, acquisition, and extinction of eyelid responses (Gruart et al. 2006; and see Materials and Methods). Concordant with a previous study (Gruart et al. 2006), in the absence of any conditioning stimulus, the slope of fEPSPs evoked by the stimulation of Schaffer collaterals (60 times per day) was stable across the maximum period of time used in classical conditioning studies $(\sim 30 \mathrm{~d})$, indicating that electrical stimulation per se, at this rather low rate, did not modify the fEPSP profiles with time (A. Gruart and L. Minichiello, data not shown).

The results obtained during in vivo recordings of eyelid responses showed a significant increase in the percentage of conditioned responses (CRs) during conditioning sessions for all the groups $(P<0.01$, Fig. $1 \mathrm{C}, \mathrm{D})$ compared with pseudoconditioned animals, which did not show any significant change across sessions $\left(P=0.736\right.$, Fig. 1B; specifically, $+/+:\left[F_{(18,162)}=176.6\right.$; $P<0.001] ; \operatorname{trkB}^{W /+}:\left[F_{(18,162)}=115.9 ; P<0.001\right] ; \operatorname{trkB} B^{S H C /+}$ : $\left[F_{(18,162)}=97.5 ; P<0.01\right] ;$ and $\operatorname{trk} B^{P L C /+}:\left[F_{(18,162)}=78.3\right.$; $P<0.01])$. These results indicated that all groups were able to acquire trace-conditioned eyelid responses. The learning curves for $+/+$ and $t r k B^{S H C /+}$ groups were similar $(\geq 60 \%$ of CRs by the sixth conditioning session). Significant differences were observed only during the fourth to sixth conditioning sessions $\left(F_{[18,162]}=152.5 ; P \leq 0.05\right)$, with the two groups reaching a similar learning level by the tenth conditioning session (Fig. 1D). The $t r k B^{P L C /+}$ mice showed significantly lower acquisition of this associative learning paradigm compared with their controls $\left(\operatorname{trk} B^{W /+}\right)$ ( $<40 \%$ of CRs compared with $\geq 50 \%$ of the $t r k B^{W /+}$ ), specifically from the fourth to the tenth conditioning session, and from the

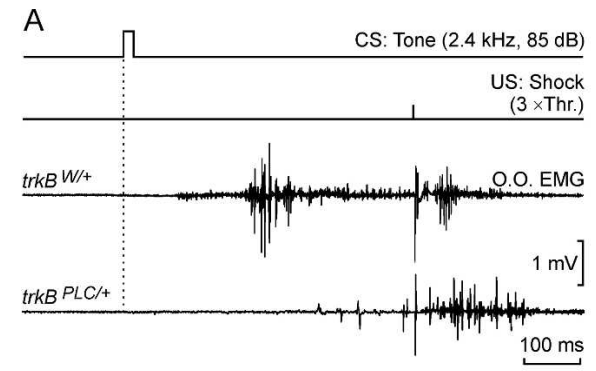

B

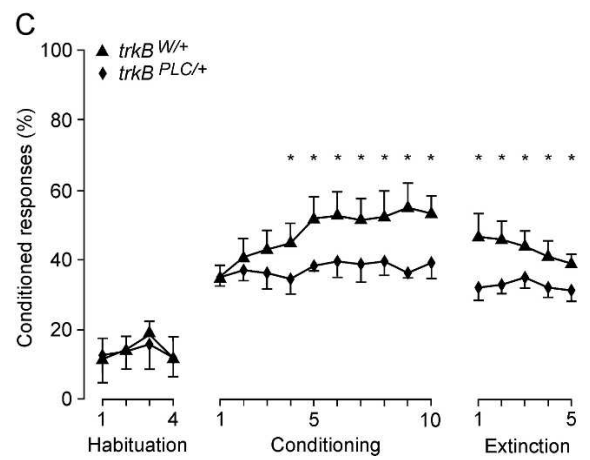

$\triangle \operatorname{trkBW++}$ $\therefore$ trkB PLC/+ o trkB $S H C /+$
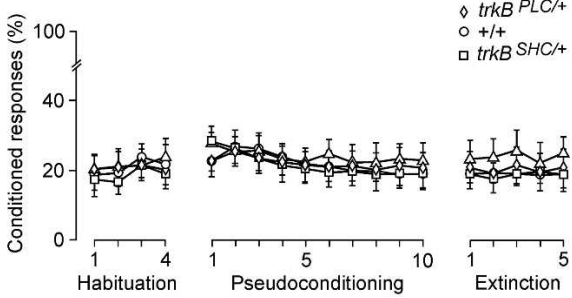

$\mathrm{D}$

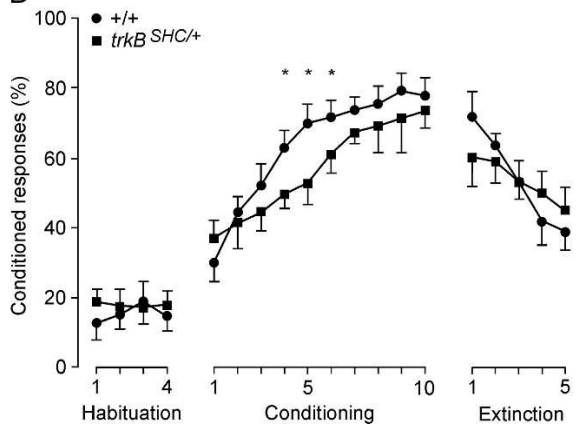

Figure 1. Point mutation at the PLC $y$-docking site but not the Shc-docking-site in TrkB impairs acquisition of associative learning. $(A)$ The top two lines represent the conditioning paradigm, illustrating CS and US. The third trace is an EMG recording from the orbicularis oculi (O.O.) muscle obtained during the seventh conditioning session from a control $\left(\operatorname{trk} B^{W /+}\right)$ animal, while the fourth trace was collected from a $t r k B^{P L C /+}$ animal also during the seventh session. $(B-D)$ Evolution of $C R$ percentage (\%) during the successive sessions for pseudoconditioned $(B)$, conditioned $\operatorname{trk} B^{W /+}$ and $\operatorname{trk} B^{P L C /+}(C)$, and $+/+$ and $\operatorname{trk} B^{S H C /+}(D)$ animals. Mean \% values are followed by $\pm S E M$. For all conditioned groups $(C, D)$, the number of $C$ Rs increased significantly $(P<0.01)$ across conditioning sessions as compared with habituation sessions, while pseudoconditioned groups $(B)$ did not show a significant increase in $C R s$ across conditioning sessions $(P=0.736)$. (Asterisks in $C, D)$ Significant differences be- 
first to the fifth extinction sessions $\left(F_{[18,162]}=135.3 ; P \leq 0.05\right)$ (Fig. 1C).

We measured in parallel the evolution of CA3-CA1 synaptic field potential during the classical conditioning or pseudoconditioning of eyelid responses in control and trkB point mutant mice. The electrical stimulation of Schaffer collaterals in the CSUS interval evoked a fEPSP in the recording (CA1) area (Fig. 2A). It should be noted that although the stimuli presented to Schaffer collaterals disrupted the regular theta rhythm recorded in the CA1 area, the rhythm reappeared in phase 100-200 msec later. fEPSPs evoked in the four experimental groups by this protocol increased progressively in slope during conditioning (Fig. 2C,D). Specifically, the fEPSPs evoked at CA3-CA1 synapses increased from $100 \%$ (which is the mean slope of fEPSPs collected during the four habituation sessions) to $\sim 120 \%$ during the eighth through tenth sessions for the $+/+$ and the $t r k B^{W /+}$ control mice (Fig. 2C,D). The fEPSP slope values for the $t r k B^{S H C /+}$ mutants increased $>125 \%$ during the eighth through tenth sessions, which was significantly larger than in $+/+$ mice $\left(F_{[18,162]}=117.6\right.$; $P<0.05$; Fig. 2D), whereas the fEPSP slope recorded in the $t r k B^{P L C /+}$ mice was significantly lower than in $\operatorname{trk} B^{W /+}$ control mice $\left(F_{[54,486]}=36.5 ; P<0.001\right.$; Fig. 2C). In fact, $\operatorname{trk} B^{P L C /+}$ fEPSP slopes during conditioning were not significantly different $(P=0.56)$ from baseline records (Fig. 2C). As expected (Gruart et al. 2006), during extinction the fEPSP slope decreased below baseline val-
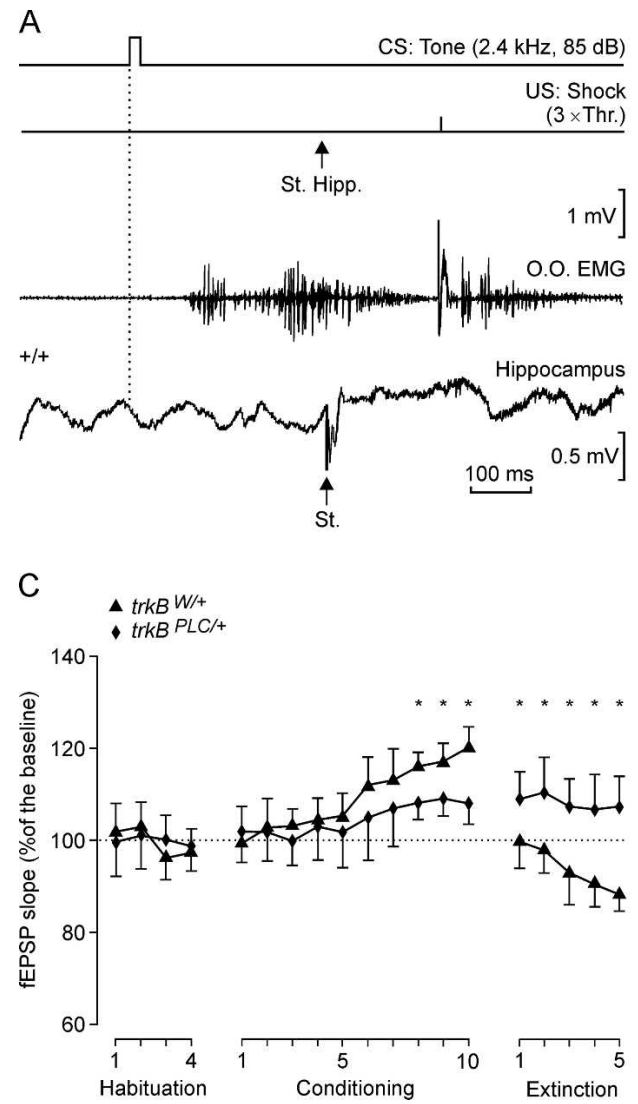

ues (by the fifth session) for the $+/+(80 \%)$ and $t r k B^{W /+}(90 \%)$ control mice (Fig. 2C,D). In contrast, fEPSP values collected from the $\operatorname{trk} B^{S H C /+}$ and $\operatorname{trk} B^{P L C /+}$ mice remained at the level reached during the tenth conditioning session for the five extinction sessions (Fig. 2C,D). Together, these data indicate that the physiological potentiation occurring at the CA3-CA1 synapse in parallel with the acquisition of classical conditioning of eyelid responses depends on the activation of pathway(s) through the TrkB PLC $\gamma$-docking site. In contrast, mice carrying a point mutation at the SHC-docking site of TrkB seem unable to extinguish the increase in CA3-CA1 synaptic strength evoked by trace conditioning. As indicated above with respect to the percentage of CRs in pseudoconditioned animals, fEPSP values collected from the four pseudoconditioned groups did not present any significant change in slope during habituation, conditioning, and extinction sessions. The percentage of variation across conditioning and extinction sessions when compared with the mean slope $(100 \%)$ of fEPSPs collected during the four habituation sessions was $\leq 13.2 \%$, with no statistically significant tendency toward an increase or a decrease ( $P \geq 0.62$; Fig. $2 \mathrm{~B})$. As already reported for basal synaptic transmission in the hippocampus during acute (Gilbert and Mack 1999) and chronic (Gruart et al. 2006) recordings, pseudoconditioned animals (both control and mutant mice) did not present any significant change in basal fEPSP slopes for up to $19 \mathrm{~d}$.

B
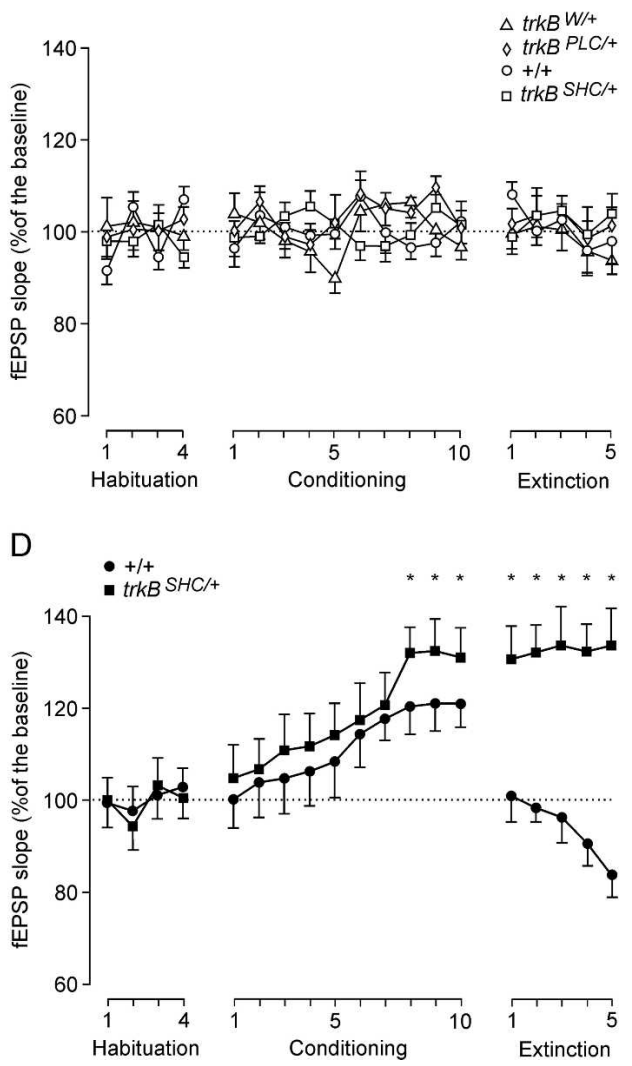

Figure 2. In vivo fEPSP recordings from the hippocampal CA1 pyramidal cells during habituation, acquisition, and extinction of eyelid responses. ( $A$ ) Schematic representation of the conditioning paradigm, illustrating CS and US, and when a single pulse (100- $\mu$ sec, biphasic) was presented to Schaffer collaterals (St. Hipp). An example of an EMG recording from the O.O. muscle obtained during the seventh conditioning session is illustrated, as well as an extracellular recording of hippocampal activity from the same animal $(+/+)$ and session (seventh). Note the fEPSP evoked by the single pulse presented to Schaffer collaterals. $(B, C, D)$ Evolution of fEPSP slopes across habituation, conditioning, and extinction sessions for pseudconditioned $(B)$, trkB $B^{W /+}$ and $\operatorname{trk} B^{P L C /+}(C)$, and $+/+$ and $\operatorname{trk} B^{S H C /+}(D)$ animals.

\section{Learning \& Memory}

www.learnmem.org 
TrkB PLC $\gamma$ site, learning, and synaptic potentiation

Linear relationship between acquisition of eyeblink conditioning and plastic changes at the CA3-CAI

\section{synapses}

The slope of fEPSPs evoked by Schaffer collateral stimulation at the CA3-CA1 synapse in $+/+$ mice correlated $(r \geq 0.69 ; P<0.001)$ with the percentage of CRs during conditioning (slope $=1.66$ ) and extinction (slope $=1.01$ ) sessions, but not during habituation (Fig. 3A). Similar linear relationships between fEPSP slope and percentage of CRs for conditioning $(r=0.69 ; P<0.001)$ and extinction $(r=0.75 ; P<0.001)$ sessions were obtained for the $t r k B^{W /+}$ control mice (Fig. 3B). The fact that the regression lines for acquisition and extinction sessions presented similar slopes suggests that the activity-dependent plasticity at the CA3-CA1 synapse functioned as a continuum for both acquisition and extinction processes in control mice $\left(+/+\right.$ and $\left.t r k B^{W /+}\right)$. The $t r k B^{S H C /+}$ mutants showed a significant $(r=0.82 ; P<0.001)$ relationship between fEPSP slope and the percentage of CRs only during the conditioning session (Fig. 3C), while the $t r k B^{P L C /+}$ mutant mice did not present any significant relationship between the two parameters in either the conditioning or the extinction sessions (Fig. 3D). These results indicate that activity-dependent plasticity at the CA3-CA1 synapses during the acquisition of associative learning requires an intact TrkB PLC $\gamma$-docking site.

\section{BDNF facilitation process requires the TrkB PLC $\gamma$ site}

The facilitation evoked by the presentation of a pair of pulses is a typical presynaptic short-term plastic property of some excitatory synapses of the hippocampus, including the CA3-CA1 syn- apses, and it has been correlated with neurotransmitter release (Zucker and Regehr 2002). It is expected that animals present a larger fEPSP response to the second (with respect to the first) stimulus at short intervals $(<100 \mathrm{msec})$. Recently, it has been shown that BDNF acts on presynaptic glutamatergic terminals and facilitates $\mathrm{K}^{+}$-evoked glutamate release (Canas et al. 2004). Here we have tested the $t r k B$ point mutants and control mice for enhancement of synaptic transmission. As illustrated in Figure $4 \mathrm{~B}$, control $(+/+)$ mice presented a significant $(P<0.01)$ increase in response to the second pulse at short time intervals $(20 \mathrm{msec})$. $t r k B^{W /+}$ and $t r k B^{S H C /+}$ mice also presented a paired-pulse facilitation at an interval of $20 \mathrm{msec}$, though to a lesser extent compared with the $+/+$ group $\left(F_{[15,135]}=8.4, P<0.01\right)$. Interestingly, the $\operatorname{trkB} B^{P L C /+}$ group presented delayed facilitation $(100 \mathrm{msec})$ for the paired-pulse test (Fig. 4A,B). The values collected for the $t r k B^{P L C /+}$ group, at 20-msec intervals, were significantly lower $(P<0.001)$ than those collected for control $\left(+/+\right.$ and $\left.t r k B^{W /+}\right)$ and $t r k B^{S H C /+}$ groups (Fig. 4A,B). These results indicate that the BDNF/TrkB facilitation process is an important step in the generation of CRs during associative learning, and requires one or more TrkB PLC $\gamma$ site-activated pathway(s).

\section{The TrkB PLC $\gamma$ site is required for synaptic strengthening in vivo}

To further investigate the deficit in synaptic plasticity observed in the $t r k B^{P L C /+}$ group at CA3-CA1 synapses, we examined potentiated fEPSP responses that can last for hours to days. In order to obtain baseline recordings, Schaffer collaterals were stimulated every $5 \mathrm{sec}$ for $15 \mathrm{~min}$. The stimulus consisted of a $100-\mu \mathrm{sec}$,
A

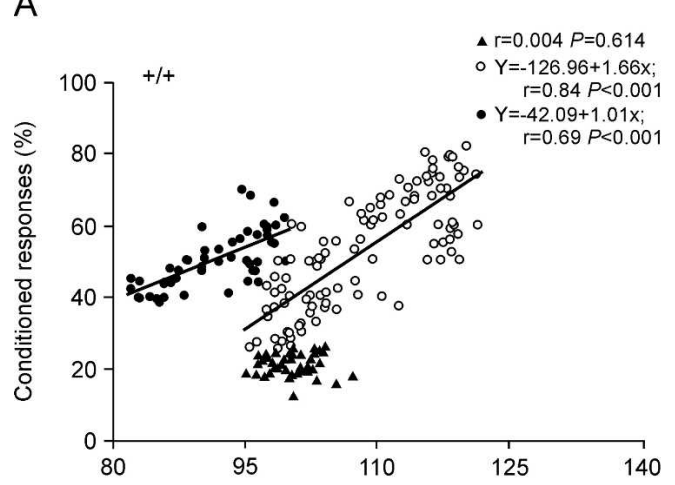

C

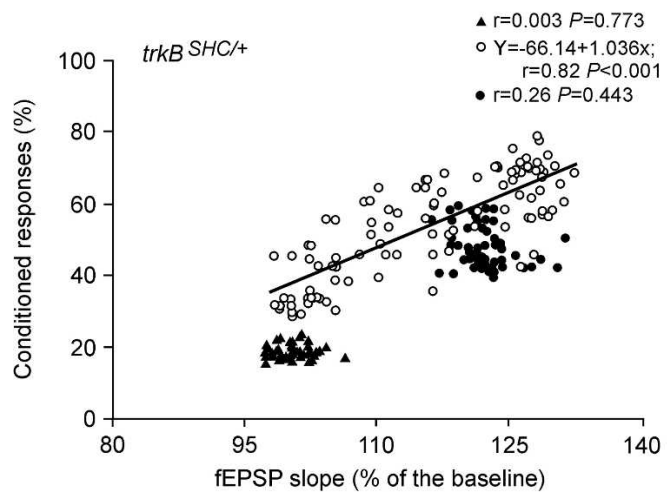

B

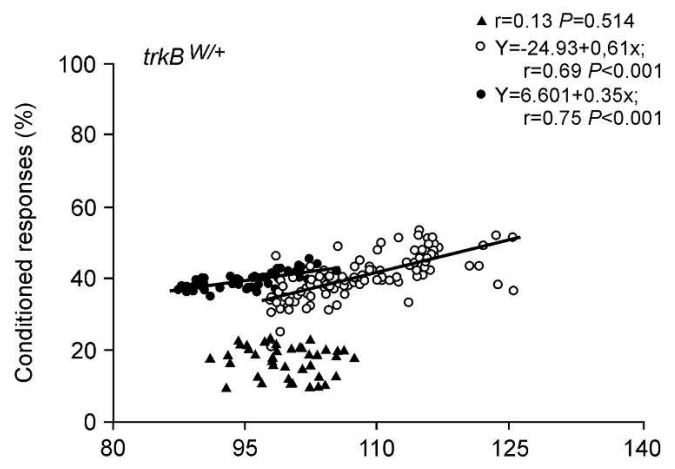

D

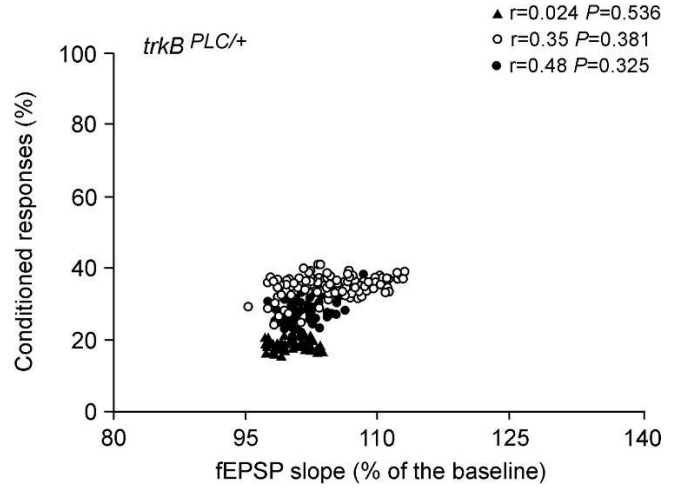

Figure 3. Quantitative analysis of the relationships between fEPSP slope and the percentage of CRs for the four experimental groups. Data collected from $+/+(A)$, trkB $B^{W /+}(B)$, trkB $B^{S H C /+}(C)$, and trkB $B^{P L C /+}(D)$ groups are illustrated. Each point represents the mean value collected from a single animal during the corresponding session. Data are represented separately for habituation (black triangles), conditioning (open circles), and extinction (dots) sessions. Regression lines, and their corresponding equations, are included only for coefficients of correlation, $r>0.65$. $P$-values for each regression analysis are also indicated. 
A

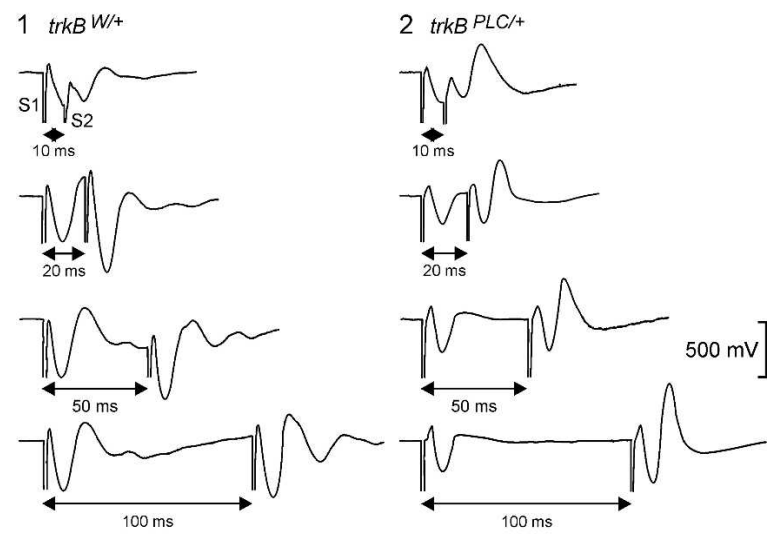

B

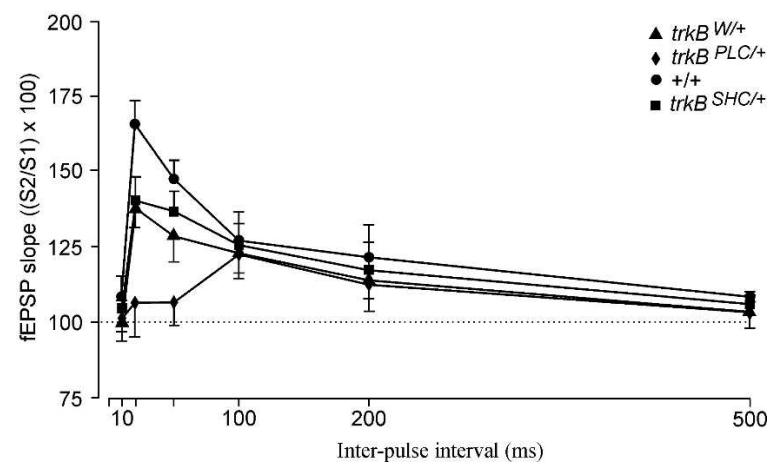

Figure 4. Paired-pulse facilitation of fEPSP recordings in the CA1 area following stimulation of Schaffer collaterals. (A) Extracellular fEPSP paired traces collected for the $\operatorname{trk} B^{W /+}(1)$ and $t r k B^{P L C /+}$ (2) groups at inter-pulse intervals of 10,20,50, and $100 \mathrm{msec}$. (B) The data shown are mean \pm SEM slopes of the second fEPSP expressed as a percentage of the first $([S 2 / S 1] \times 100)$ for the six inter-stimulus intervals used in this study.

square, biphasic pulse. Pulse intensity (50-350 $\mu \mathrm{A})$ was set at $30 \%-40 \%$ of the amount necessary to evoke a maximum fEPSP response. LTP was evoked by presenting each animal with highfrequency stimulation (HFS) consisting of five trains $(200 \mathrm{~Hz}, 100$ msec) of pulses at a rate of one per second. This protocol was presented six times in total at intervals of $1 \mathrm{~min}$. In order to avoid evoking a population spike and/or unwanted EEG seizures, the stimulus intensity was set as that used for generating the baseline recording. After HFS, the same single stimulus was presented at the initial rate (12 per minute) for another $120 \mathrm{~min}$ (Fig. 5). With this protocol, all experimental groups presented significant LTP $\left(F_{[36,324]}=115.3 ; P<0.001\right)$. However, the LTP response $10 \mathrm{~min}$ after HFS resulted in $190 \%$ of baseline values for the $\operatorname{trkB} B^{S H C /+}$ mice, and $\sim 160 \%$ for the $+/+$ group, with similar values for the trkB $B^{W+}$ mice $(\sim 150 \%)$; the $\operatorname{trk} B^{P L C /+}$ group presented the lowest values $(140 \% ; P<0.05$; Fig. $5 \mathrm{~A}, \mathrm{~B})$. At the end of the recording time $(120 \mathrm{~min}), \mathrm{LTP}$ values for the $+/+$ and $t r k B^{S H C /+}$ mice were similar ( 130\%-140\% higher than baseline values), while values for the $t r k B^{P L C /+}$ group were still significantly lower $(<20 \%$ increase in fEPSP slope; $P<0.05$ ) than control $t r k B^{W /+}$ mice (Fig. $5 \mathrm{C}, \mathrm{D})$. These results are in agreement with our previous finding obtained by evoking LTP in hippocampal slices (Minichiello et al. 2002), and indicate that the TrkB PLC $\gamma$ site is required for synaptic strengthening in vivo.

\section{Discussion}

Understanding whether the molecular pathways required for learning are also those generating LTP when measured directly on the relevant circuit of a learning animal is clearly important, and technically difficult. Here, by combining highly defined genetic mouse models (mice carrying point mutations on specific docking sites of TrkB receptors, the $\operatorname{trk} B^{S H C}$, and the $\operatorname{trk} B^{P L C} \mathrm{mu}$ tants) with an innovative method of checking synaptic strength during the trace eyeblink conditioning trials, we examined learning-related developments in synaptic efficacy in the CA3-CA1 hippocampal region. We found that mice with a mutation at the TrkB PLC $\gamma$-docking site are impaired in the acquisition of trace eyeblink conditioning, and also show impairments in learningrelated changes in synaptic efficacy and LTP in the CA3-CA1 region. In contrast, mice with a mutation at the TrkB SHCdocking site showed normal acquisition of trace eyeblink conditioning, but to some extent augmented synaptic efficacy and LTP. Together, these results indicate that one or more TrkB PLC $\gamma$ site-activated molecular pathway(s) underlie both associative learning and LTP triggered at the CA3-CA1 synapse.

\section{The TrkB PLC $\gamma$ site couples learning and CA3-CA1 LTP in vivo}

The involvement of hippocampal circuits for the classical conditioning of eyelid responses is generally accepted (Berger et al. 1983; Moyer et al. 1990). By using unitary in vivo recordings, it has been shown that hippocampal pyramidal cell firing to CS presentations increases across conditioning sessions (McEchron and Disterhoft 1997; Múnera et al. 2001; McEchron et al. 2003), a fact confirmed here with the increasing slope of the fEPSP evoked at the apical dendrites of pyramidal CA1 neurons by single pulses presented to Schaffer collaterals. Indeed, it was shown years ago that the efficacy of synaptic activation of dentate granule cells by perforant pathway axons was modified during the acquisition of nictitating membrane CRs in rabbits (Weisz et al. 1984). Moreover, it has been also shown in vitro that associative learning enhances CA3-CA1 synaptic transmission immediately after training (Power et al. 1997).

The slow building up of the hippocampal neuronal response across conditioning sessions is similar to the small increase in the slope of the fEPSP evoked at the apical dendrites of CA1 pyramidal cells by single pulses applied to Schaffer collaterals (i.e., a $0.2 \%$ increase in fEPSP slope/trial collected for the +/+ group). These results suggest that the fEPSP slope is related to the actual firing of identified hippocampal pyramidal neurons, and are supported by previous studies in the cat and the mouse (Múnera et al. 2001; Gruart et al. 2006). The fEPSP slopes collected from the CA3-CA1 synapse across learning presented a linear relationship with the percentage of CRs for both acquisition and extinction in controls (+/+ and $t r k B^{W /+}$ groups), or only for acquisition in the trkB $B^{S H C /+}$ group, whereas no linear relationship was present in the $\operatorname{trk} B^{P L C /+}$ group, indicating that the activation of one or more pathways through the PLC $\gamma$-docking site is required for both associative learning and CA3-CA1 LTP in vivo. These data are in agreement with our previous findings indicating that the TrkB PLC $\gamma$-docking site is necessary for certain forms of learning and hippocampal synaptic plasticity studied by in vitro electrophysiology (Minichiello et al. 1999, 2002), and further strengthen a genetic link between learning and LTP triggered at CA1 synapses. However, since this mutation is ubiquitous, further work is needed to determine the contribution of other brain structures to the learning defect observed in this study.

\section{What is the relationship between classical conditioning of eyelid responses and LTP?}

LTP is a fundamental property of most excitatory synapses in the mammalian brain. In the CA1 region of the hippocampus, LTP is 
A

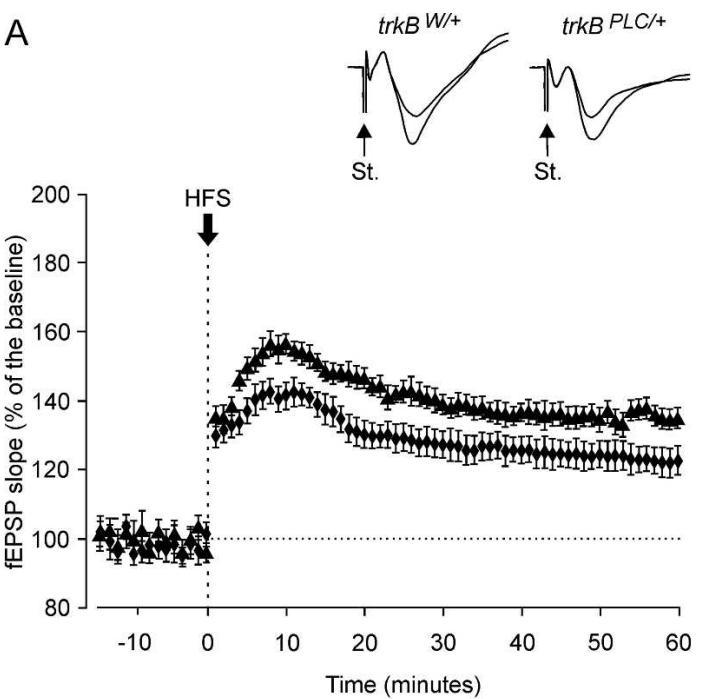

C

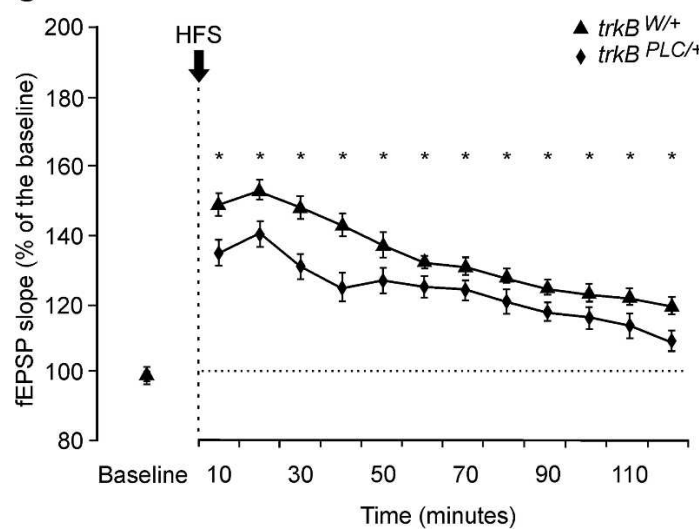

B
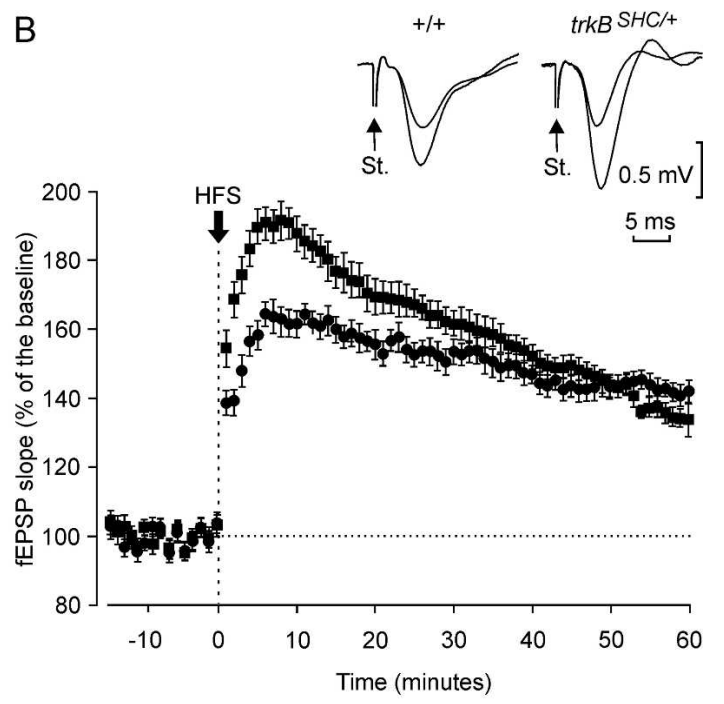

D

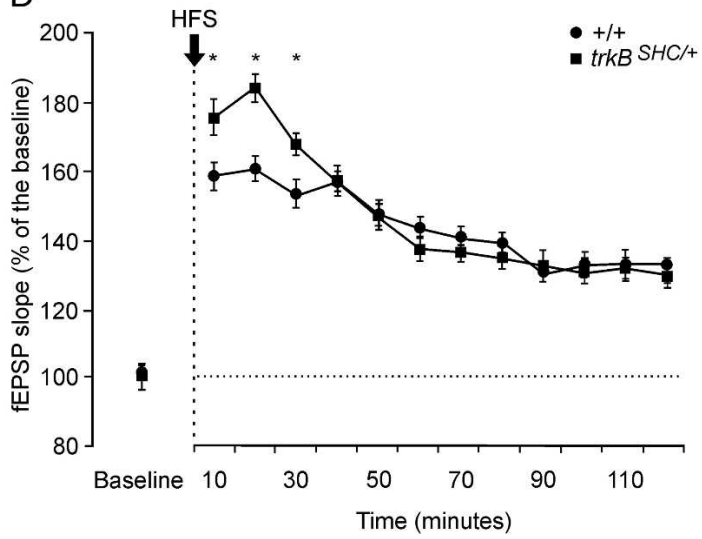

Figure 5. LTP induction in the CA1 area following electrical stimulation of the Schaffer collaterals. $(A, B)$ At the top are illustrated examples collected from selected animals of each experimental group. In all cases, the smaller fEPSP was collected before the HFS, while the larger one was collected 10 min after the HFS. Calibration in $B$ is also for $A$. The bottom graphs illustrate the time course of changes in fEPSP (mean \pm SEM) following tetanic (HFS) stimulation of the Schaffer collaterals. The HFS was presented after 15 min of control recordings, at the time marked by the arrow. The fEPSP is given as a percentage of the baseline (100\%) slope. Data in $A$ correspond to $t r k B^{W /+}$ and $\operatorname{trk} B^{P L C /+}$ groups, while those in $B$ correspond to $+/+$ and $t r k B^{S H C /+}$ animals. $(C, D)$ Evolution of LTP evoked in the CA1 area during the $2 \mathrm{~h}$ following HFS for the $\operatorname{trk} B^{W /+}$ and $t r k B^{P L C /+}(C)$ and $+/+$ and $t r k B^{S H C /+}(D)$ groups. (Asterisks in $C, D)$ Significant differences between groups $(P \leq 0.05)$.

input-specific, meaning that the increase in synaptic strength normally occurs only at the set of synapses in which LTP has been generated by repetitive activation. In contrast, the generation of eyelid CRs is a slow process requiring a large number $(<300)$ of paired CS-US presentations (Woody 1986). However, LTP is also associative, indicating that a weak input can still be potentiated if activated simultaneously with (or within a given time window of) a strong stimulus evoked through a separate but convergent input (McNaughton et al. 1978; Levy and Steward 1983; Bliss and Collingridge 1993). Thus, it is feasible to suggest that the potentiation process observed here at the CA3-CA1 synapse during the classical conditioning of eyelid responses resembles the LTP mechanism evoked experimentally by in vitro procedures.

\section{The BDNF/TrkB facilitation process is a necessary step for CR generation}

It is known that BDNF plays an important role in the mobilization and docking of synaptic vesicles in presynaptic active zones of the hippocampal circuit (Pozzo-Miller et al. 1999; Xu et al. 2000). In this regard, and as shown by Gottschalk et al. (1998) in hippocampal slices, the lack of BDNF has an evident effect on double-pulse facilitation, mainly at short intervals ( $>30 \mathrm{msec}$ ). The double-pulse paradigm used here, in vivo, also indicates a deficit in double-pulse facilitation for short (>100-msec) intervals in $t r k B^{P L C /+}$ animals. Thus, these results suggest that the facilitation process of BDNF on presynaptic terminals is an important and necessary step for the generation of CRs during associative learning, and depends on a functional TrkB-PLC $\gamma$ docking site. Moreover, the CA3-CA1 synaptic strength needs not only to be actively potentiated across conditioning sessions, but also to be linearly related to the intrinsic neural mechanisms responsible for the generation of the eyelid CR.

The BDNF/TrkB system and the process of extinction Extinction is the result of repetitive CS presentations in the absence of the US. In fact, it has been recently shown that the extinction process, like acquisition of classically conditioned eyelid responses, requires de novo protein synthesis (Inda et al. 2005), suggesting that extinction is an active learning process by which previously established responses are suppressed. Here, we show that $t r k B^{P L C /+}$ mice were unable to present an appropriate 
extinction response of the acquired CRs (Fig. 1C). Moreover, the fEPSPs evoked in $t r k B^{P L C /+}$ mice did not decrease in slope across the successive extinction sessions as in control mice (Fig. 2C). Together, these results indicate that the BDNF/TrkB system through the PLC $\gamma$-docking site is necessary for the extinction of acquired CRs. However, the $t r k B^{S H C /+}$ group also presented abnormal fEPSP responses during the extinction process (Fig. 2D), indicating a dissociation between the extinction process and the acquired synaptic strength during conditioning sessions. In this regard, it can be suggested that the BDNF/TrkB system functions differently during the acquisition and extinction of conditioned eyelid responses. Moreover, and assuming that the hippocampal circuits are more related to the CS salience and/or CS-US associative strength (Múnera et al. 2001), it can be proposed that the $t r k B^{S H C /+}$ animals are unable to disassociate the two stimuli (CS and US) from a cognitive point of view, although the acquired motor response is extinguished as in controls.

However, associative learning involves the recruitment of different brain structures (hippocampus, amygdala, prefrontal and motor cortices, cerebellum) for different aspects (CS-US associative strength, conditioned motor response, enhancement of the acquired ability) of the classically conditioned motor response (Bechara et al. 1995; Powell et al. 1996; Weible et al. 2003; Thompson 2005; Delgado-García and Gruart 2006). Particularly, the amygdala and the prefrontal cortex seem to be involved in trace conditioning when a shock is used as a US (Powell et al. 1996). In this regard, it has recently been proposed that the caudal medial prefrontal cortex is critical for the acquisition of hippocampus-dependent trace eyeblink conditioning, whilst the rostral medial prefrontal cortex is more related with the extinction of the acquired CR (Weible et al. 2000). Although the stimulus used here as a US did not seem to evoke any sign of discomfort in experimental animals, the involvement of TrkB-dependent signaling in these cortical and subcortical structures may influence the acquisition and/or extinction of the eyeblink task.

\section{Mutation of the TrkB SHC-docking site does not affect trace-conditioned eyeblink responses}

Our results show that mice with a mutation at the TrkB SHCdocking site have normal acquisition of trace eyeblink conditioning. Significant differences (between the wild-type and $t r k B^{S H C /+}$ groups) were observed only during the fourth to sixth conditioning sessions $\left(F_{[18,162]}=152.5 ; P \leq 0.05\right)$, with the two groups reaching a similar learning level by the tenth conditioning session (Fig. 1D). For this reason, we consider the two groups as having acquired a similar level of conditioning. Moreover, as illustrated in Figure 3, A and C, both groups presented similar (significant) linear relationships between their learning curves and the increase in fEPSP slope. The $t r k B^{S H C /+}$ group, in addition, presented an enhancement in synaptic strength in vivo after HFS as compared with +/+ controls. As this phenomenon was observed only in the first $10 \mathrm{~min}$ of the recordings, and that soon afterward values were similar until the end of the recording time (120 min), it suggests a similar expression of hippocampal LTP in the wild-type and $t r k B^{S H C /+}$ mutant mice.

\section{Conclusions}

The present results indicate that the physiological potentiation occurring at the CA3-CA1 synapse in parallel with the acquisition of classical conditioning of eyelid responses depends on the activation of pathway(s) through the TrkB PLC $\gamma$-docking site. These data are in agreement with our previous findings indicating that the TrkB PLC $\gamma$-docking site is necessary for certain forms of learning and hippocampal synaptic plasticity studied by in vitro electrophysiology (Minichiello et al. 1999, 2002). The great difference is that we have now been able to start dissecting molecular pathways underlying both acquisition of associative learning and the physiological increase in synaptic strength in the CA3-CA1 region in alert behaving animals by combining highly defined genetic mouse models with an innovative method of checking CA3-CA1 synaptic strength during the trace eyeblink conditioning trials.

\section{Materials and Methods}

\section{Mouse strains}

Generation of TrkB point mutant mice has been described previously (Minichiello et al. 1998, 2002). Briefly, we have used the cDNA "knock-in" approach (Hanks et al. 1995) to introduce a point mutation at the PLC $\gamma$-docking site in the carboxy-terminal region of the TrkB receptor. Tyrosine 816 (Y816) was changed into phenylalanine $(\mathrm{F})$ in the mouse trkB cDNA to disrupt the binding of adaptor proteins and the signaling events mediated by the PLC $\gamma$-docking site. Mutant trkB cDNA and wild-type trkB cDNA (as a control for the strategy) were fused to the juxtamembrane exon of the mouse $t r k B$ gene, and standard homologous recombination in ES cells (E14.1) was used to generate the targeted trkB $B^{P L C}$ and $t r k B^{W T}$ alleles (Minichiello et al. 2002). To generate the $t r k B^{S H C}$ allele, we have used the "touch and go" strategy to introduce a point mutation at the SHC-docking site in the juxtamembrane region of the TrkB receptor. Tyrosine 515 (Y515) was changed into F (F515) in the mouse trkB genomic DNA to disrupt the binding of adaptor proteins and the signaling events mediated by the SHC-docking site. Standard homologous recombination in ES cells (R1) was used to generate the targeted $t r k B^{S H C}$ allele (Minichiello et al. 1998).

\section{Experimental setup}

Animals were $4 \pm 1$-mo-old at the time of surgery, weighing $32 \pm 2$ g. Electrophysiological and behavioral studies were carried out as previously described (Gruart et al. 2006), and in accordance with the guidelines of the European Union Council $(86 / 609 / \mathrm{EU})$ and Spanish regulations (BOE 67/8509-12, 1988) for the use of laboratory animals in chronic experiments. For conditioning and pseudoconditioning sessions, 10 animals were used for each experimental group. Double-pulse and long-term potentiation (LTP) studies were carried out on 10 additional animals per group.

\section{Classical conditioning procedures}

For classical conditioning recordings, two animals at a time were placed in separate small $(5 \times 5 \times 10-\mathrm{cm})$ plastic chambers located inside a Faraday box $(30 \times 30 \times 20 \mathrm{~cm})$. Classical conditioning was achieved using a trace paradigm (Fig. 1A) consisting of a tone (20 msec, $2.4 \mathrm{kHz}, 85 \mathrm{~dB})$ presented as a CS, and a cathodal pulse applied to the supraorbitary nerve $(500 \mu \mathrm{sec}, 3 \times$ threshold, square) as a US. The US started $500 \mathrm{msec}$ after the end of the CS. Animals received just one training session per day. A total of four habituation, 10 conditioning, and five extinction sessions were carried out for each animal. A conditioning session consisted of 60 CS-US presentations, and lasted $\sim 30 \mathrm{~min}$. For a proper analysis of the CR, the CS was presented alone in $10 \%$ of the cases. CS-US presentations were separated at random by $30 \pm 5 \mathrm{sec}$. For habituation and extinction sessions, only the CS was presented, also for 60 times per session, at intervals of $30 \pm 5$ sec. For pseudoconditioning, unpaired CS and US presentations were carried out for 10 sessions (60 times per session). Pseudoconditioned animals also received four habituation and five extinction sessions as indicated above (Domínguez-del-Toro et al. 2004). Eyelid responses were determined by the EMG activity of the orbicularis oculi muscle ipsilateral to the US. The electrical stimulation $(2 \times$ threshold) of the supraorbitary branch of the trigeminal nerve ( $n=5$ animals) evoked an early EMG activation of the orbicularis oculi muscle at a latency of 4-5 msec, followed by a second EMG activation, with latency from the stimulus of 15-20 msec. These successive muscle activations correspond to 
the R1 and R2 components already described in humans (Kugelberg 1952) and other mammals, including mice (Domínguez-delToro et al. 2004; Gruart et al. 2006).

\section{Hippocampal recording and stimulation procedures}

Recordings were made using Grass P511 differential amplifiers with a bandwidth of $0.1 \mathrm{~Hz}-10 \mathrm{kHz}$ (Grass-Telefactor). Hippocampal recordings were made with a high-impedance probe $\left(2 \times 10^{12} \Omega, 10 \mathrm{pF}\right)$. As criteria, we considered a "CR" the presence, during the CS-US period, of EM activity lasting $>10 \mathrm{msec}$ and initiated $>50 \mathrm{msec}$ after CS onset. In addition, the integrated EMG activity recorded during the CS-US interval had to be at least $2.5 \times$ greater than the averaged activity recorded immediately before CS presentation (Porras-García et al. 2005). Electrodes were surgically implanted in the CA1 area, using as a guide the field potential depth profile evoked by paired (interval of $20-50 \mathrm{msec}$ ) pulses presented at the ipsilateral Schaffer collateral pathway. The recording electrode was fixed at the site where a reliable monosynaptic fEPSP was recorded. Synaptic field potentials in the CA1 area were evoked during habituation, conditioning, and extinction sessions by a single 100 - $\mu$ sec, square, biphasic (negative-positive) pulse applied to Schaffer collaterals $300 \mathrm{msec}$ after CS presentation. Stimulus intensities ranged from 50 to 350 $\mu \mathrm{A}$. For each animal, the stimulus intensity was set well below the threshold for evoking a population spike, usually 30\%-40\% of the intensity necessary for evoking a maximum fEPSP response (Gureviciene et al. 2004). An additional criterion for selecting stimulus intensity was that a second stimulus, presented 20-100 msec after a conditioning pulse, evoked a larger (>20\%) synaptic field potential (Bliss and Gardner-Medwin 1973). In order to evoke LTP, each animal was presented with five trains of pulses $(200 \mathrm{~Hz}, 100 \mathrm{msec}$ at a rate of one per second). This protocol was presented six times in total, at intervals of $1 \mathrm{~min}$. The $100-\mu \mathrm{sec}$, square, biphasic pulses used to evoke LTP were applied at the same intensity as that used for the single pulse presented following CS presentation. At the end of the experiments, mice were deeply re-anesthetized (sodium pentobarbital, $50 \mathrm{mg} / \mathrm{kg}$ ), and perfused transcardially with saline and $4 \%$ phosphate-buffered paraformaldehyde. Selected sections $(50 \mu \mathrm{m})$ including the dorsal hippocampus were mounted on gelatinized glass slides and stained using the Nissl technique with $0.1 \%$ Toluidine blue, to determine the location of stimulating and recording electrodes (Gruart et al. 2006).

\section{Data analysis}

EMG and hippocampal activity, and 1-volt rectangular pulses corresponding to CS and US presentations, were stored digitally on a computer through an analog/digital converter (CED 1401 Plus), at a sampling frequency of $11-22 \mathrm{kHz}$ and an amplitude resolution of 12 bits. Commercial computer programs (Spike 2 and SIGAVG from CED) were modified to represent EMG and extracellular synaptic field potential recordings. Data were analyzed off-line for quantification of CRs and fEPSP slopes with the help of homemade representation programs (Gruart et al. 1995, 2000; Domínguez-del-Toro et al. 2004; Porras-García et al. 2005). Computed results were processed for statistical analysis using the SPSS for Windows package. Unless otherwise indicated, data are represented as the mean \pm SEM. Acquired data were analyzed using a two-way ANOVA test, with session, time, or interstimulus interval as the repeated measure. Contrast analysis was added to study significant differences in more detail. Regression analysis was used to study the relationship between the fEPSP slope and the percentage of conditioned responses.

\section{Acknowledgments}

This work was partly supported by a grant from the European Union (EuroStemCell) to L.M., and grants BFU2005-01024 and BFU2005-02512 to J.M.D.G. and A.G. We thank Dr. C. Serguera for critical reading of the manuscript and Ms. María Esteban for contributing to the editing of the figures.

\section{References}

Bechara, A., Tranel, D., Damasio, H., Adolphs, R., Rockland, C., and Damasio, A.R. 1995. Double dissociation of conditioning and declarative knowledge relative to the amygdala and hippocampus in humans. Science 269: 1115-1118.

Berger, T.W., Rinaldi, P., Weisz, D.J., and Thompson, R.F. 1983. Single-unit analysis of different hippocampal cell types during classical conditioning of rabbit nictitating membrane response. $J$. Neurophysiol. 50: 1197-1219.

Bibel, M. and Barde, Y.A. 2000. Neurotrophins: Key regulators of cell fate and cell shape in the vertebrate nervous system. Genes \& Dev. 14: 2919-2937.

Bliss, T.V.P. and Collingridge, G.L. 1993. A synaptic model of memory: Long-term potentiation in the hippocampus. Nature 361: 31-39.

Bliss, T.V.P. and Gardner-Medwin, A.R. 1973. Long-lasting potentiation of synaptic transmission in the dentate area of the unanaesthetized rabbit following stimulation of the perforant path. J. Physiol. 232: $357-374$

Canas, N., Pereira, I.T., Ribeiro, J.A., and Sebastiao, A.M. 2004. Brain-derived neurotrophic factor facilitates glutamate and inhibits GABA release from hippocampal synaptosomes through different mechanisms. Brain Res. 1016: 72-78.

Delgado-García, J.M. and Gruart, A. 2006. Building new motor responses: Eyelid conditioning revisited. Trends Neurosci. 29: 330-338.

Domínguez-del-Toro, E., Rodríguez-Moreno, A., Porras-García, E., Sánchez-Campusano, R., Blanchard, V., Lavilla, M., Böhme, G.A., Benavides, J., and Delgado-García, J.M. 2004. An in vitro and in vivo study of early deficits in associative learning in transgenic mice that over-express a mutant form of human APP associated with Alzheimer's disease. Eur. J. Neurosci. 20: 1945-1952.

Gilbert, M.E. and Mack, C.M. 1999. Field potential recordings in dentate gyrus of urethane anesthetized rats: Stability of baseline. Hippocampus 9: 277-287.

Gottschalk, W., Pozzo-Miller, L.D., Figurov, A., and Lu, B. 1998. Presynaptic modulation of synaptic transmission and plasticity by brain-derived neurotrophic factor in the developing hippocampus. $J$. Neurosci. 18: 6830-6839.

Gruart, A., Blázquez, P., and Delgado-García, J.M. 1995. Kinematics of unconditioned and conditioned eyelid movements in the alert cat. $J$. Neurophysiol. 74: 226-248.

Gruart, A., Schreurs, B.G., Domínguez-del-Toro, E., and Delgado-García, J.M. 2000. Kinetic and frequency-domain properties of reflex and conditioned eyelid responses in the rabbit. J. Neurophysiol. 83: $836-852$.

Gruart, A., Munoz, M.D., and Delgado-Garcia, J.M. 2006. Involvement of the CA3-CA1 synapse in the acquisition of associative learning in behaving mice. J. Neurosci. 26: 1077-1087.

Gureviciene, I., Ikonen, S., Gurevicius, K., Sarkaki, A., van Groen, T. Pussinen, R., Ylinen, A., and Tanila, H. 2004. Normal induction but accelerated decay of LTP in APP + PS1 transgenic mice. Neurobiol. Dis. 15: 188-195.

Hanks, M., Wurst, W., Anson-Cartwright, L., Auerbach, A.B., and Joyner, A.L. 1995. Rescue of the En-1 mutant phenotype by replacement of En-1 with En-2. Science 269: 679-682.

Inda, M.C., Delgado-Garcia, J.M., and Carrion, A.M. 2005. Acquisition, consolidation, reconsolidation, and extinction of eyelid conditioning responses require de novo protein synthesis. J. Neurosci. 25: 2070-2080.

Kandel, E.R. 2001. The molecular biology of memory storage: A dialogue between genes and synapses. Science 294: 1030-1038.

Korte, M., Carroll, P., Wolf, E., Brem, G., Thoenen, H., and Bonhoeffer, T. 1995. Hippocampal long-term potentiation is impaired in mice lacking brain-derived neurotrophic factor. Proc. Natl. Acad. Sci. 92: 8856-8860.

Kugelberg, E. 1952. Facial reflexes. Brain 75: 385-396.

Levy, W. and Steward, O. 1983. Temporal contiguity requirements for long-term associative potentiation/depression in the hippocampus. Neuroscience 8: 791-797.

Lynch, M.A. 2004. Long-term potentiation and memory. Physiol. Rev. 84: $87-136$.

Malenka, R.C. and Nicoll, R.A. 1999. Long-term potentiation-A decade of progress? Science 285: 1870-1874.

McEchron, M.D. and Disterhoft, J.F. 1997. Sequence of single neuron changes in CA1 hippocampus of rabbits during acquisition of trace eyeblink conditioned responses. J. Neurophysiol. 78: 1030-1044.

McEchron, M.D., Tseng, W., and Disterhoft, J.F. 2003. Single neurons in CA1 hippocampus encode trace interval duration during trace heart rate (fear) conditioning in rabbit. J. Neurosci. 23: 1535-1547.

McNaughton, B.L., Douglas, R.M., and Goddard, G.V. 1978. Synaptic enhancement in fascia dentata: Cooperativity among coactive 


\section{Gruart et al.}

afferents. Brain Res. 157: 277-293.

Minichiello, L., Casagranda, F., Tatche, R., Stucky, C., Postigo, A., Lewin, G., Davies, A., and Klein, R. 1998. Point mutation in trkB causes loss of NT4-dependent neurons without major effects on diverse BDNF responses. Neuron 21: 335-345.

Minichiello, L., Korte, M., Wolfer, D., Kuhn, R., Unsicker, K., Cestari, V., Rossi-Arnaud, C., Lipp, H., Bonhoeffer, T., and Klein, R. 1999. Essential role for TrkB receptors in hippocampus-mediated learning. Neuron 24: 401-414.

Minichiello, L., Calella, A., Medina, D., Bonhoeffer, T., Klein, R., and Korte, M. 2002. Mechanisms of TrkB-mediated hippocampal long-term potentiation. Neuron 36: 121-137.

Moyer, J.R.J., Deyo, R.A., and Disterhoft, J.F. 1990. Hippocampectomy disrupts trace eye-blink conditioning in rabbits. Behav. Neurosci. 104: $243-252$.

Múnera, A., Gruart, A., Muñoz, M.D., Fernández-Más, R., and Delgado-García, J.M. 2001. Discharge properties of identified CA1 and CA3 hippocampus neurons during unconditioned and conditioned eyelid responses in cats. J. Neurophysiol. 86: 2571-2582.

Patterson, S., Abel, T., Deuel, T., Martin, K., Rose, J., and Kandel, E. 1996. Recombinant BDNF rescues deficits in basal synaptic transmission and hippocampal LTP in BDNF knockout mice. Neuron 16: $1137-1145$.

Porras-García, E., Cendelin, J., Domínguez-de-Toro, E., Vozeh, F., and Delgado-García, J.M. 2005. Purkinje cell loss affects differentially the execution, acquisition and prepulse inhibition of skeletal and facial motor responses in Lurcher mice. Eur. J. Neurosci. 21: 979-988.

Powell, D.A., Maxwell, B., and Penney, J. 1996. Neuronal activity in the medial prefrontal cortex during Pavlovian eyeblink and nictitating membrane conditioning. J. Neurosci. 16: 6296-6306.

Power, J.M., Thompson, L.T., Moyer Jr., J.R., and Disterhoft, J.F. 1997. Enhanced synaptic transmission in CA1 hippocampus after eyeblink conditioning. J. Neurophysiol. 78: 1184-1187.

Pozzo-Miller, L.D., Gottschalk, W., Zhang, L., McDermott, K., Du, J.,
Gopalakrishnan, R., Oho, C., Sheng, Z.H., and Lu, B. 1999. Impairments in high-frequency transmission, synaptic vesicle docking, and synaptic protein distribution in the hippocampus of BDNF knockout mice. J. Neurosci. 19: 4972-4983.

Schinder, A.F. and Poo, M. 2000. The neurotrophin hypothesis for synaptic plasticity. Trends Neurosci. 23: 639-645.

Takatsuki, K., Kawahara, S., Kotani, S., Fukunaga, S., Mori, H., Mishina, M., and Kirino, Y. 2003. The hippocampus plays an important role in eyeblink conditioning with a short trace interval in glutamate receptor subunit d2 mutant mice. J. Neurosci. 23: 17-22.

Thompson, R.F. 2005. In search of memory traces. Annu. Rev. Psychol. 56: $1-23$.

Weible, A.P., McEchron, M.D., and Disterhoft, J.F. 2000. Cortical involvement in acquisition and extinction of trace eyeblink. Behav. Neurosci. 114: 1058-1067.

Weible, A.P., Weiss, C., and Disterhoft, J.F. 2003. Activity profiles of single neurons in caudal anterior cingulate cortex during trace eyeblink conditioning in the rabbit. J. Neurophysiol. 90: 599-612.

Weisz, D.J., Clark, G.A., and Thompson, R.F. 1984. Increased responsivity of dentate granule cells during nictitating membrane response conditioning in rabbit. Behav. Brain Res. 12: 145-154.

Woody, C.D. 1986. Understanding the cellular basis of memory and learning. Annu. Rev. Psychol. 37: 433-493.

Xu, B., Gottschalk, W., Chow, A., Wilson, R., Schnell, E., Zang, K., Wang, D., Nicoll, R., Lu, B., and Reichardt, L. 2000. The role of brain-derived neurotrophic factor receptors in the mature hippocampus: Modulation of long-term potentiation through a presynaptic mechanism involving TrkB. J. Neurosci. 20: 6888-6897.

Zucker, R.S. and Regehr, W.G. 2002. Short-term synaptic plasticity. Annu. Rev. Physiol. 64: 355-405.

Received September 12, 2006; accepted in revised form October 31, 2006.

\section{Learning \& Memory}




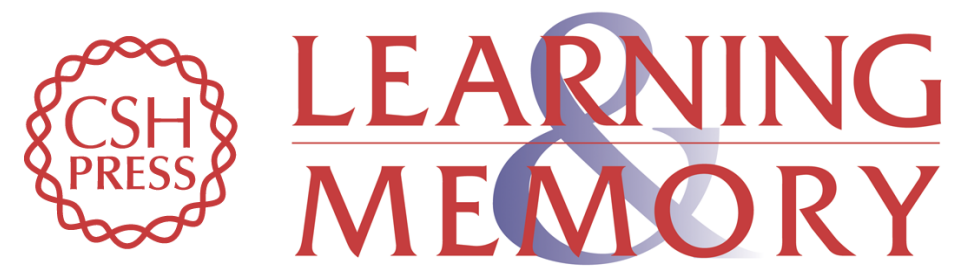

\section{Mutation at the TrkB PLC $\gamma$-docking site affects hippocampal LTP and associative learning in conscious mice}

Agnès Gruart, Carla Sciarretta, Mauricio Valenzuela-Harrington, et al.

Learn. Mem. 2007, 14:

Access the most recent version at doi:10.1101//m.428307

References This article cites 44 articles, 14 of which can be accessed free at: http://learnmem.cshlp.org/content/14/1-2/54.full.html\#ref-list-1

License Freely available online through the Learning \& Memory Open Access option.

Email Alerting Receive free email alerts when new articles cite this article - sign up in the box at the Service top right corner of the article or click here. 